\title{
Suppurative Thrombophlebitis of the Posterior Neck Caused by Streptococcus constellatus: A Case Report and Literature Review
}

\author{
Keisuke Takada, ${ }^{*, a}$ Mitsuchika Nakamura, ${ }^{b}$ Masaru Samura, ${ }^{a}$ Junki Inoue, ${ }^{a}$ Naoki Hirose, ${ }^{a}$ Takenori Kurata, ${ }^{a}$ \\ Humio Nagumo, ${ }^{a}$ Junichi Ishii, ${ }^{a}$ Sakura Koshioka, ${ }^{a}$ Koji Tanikawa, ${ }^{a}$ and Hiroyuki Kunishima ${ }^{c}$ \\ ${ }^{a}$ Department of Pharmacy, Yokohama General Hospital; 2201-5 Kurogane-cho, Aoba-ku, Yokohama 225-0025, Japan: \\ ${ }^{b}$ Department of Internal Medicine, Yokohama General Hospital; 2201-5 Kurogane-cho, Aoba-ku, Yokohama \\ 225-0025, Japan: and 'Department of Infectious Diseases, St. Marianna University School of Medicine \\ Hospital: 2-16-1 Sugao, Miyamae-ku, Kawasaki 216-8511, Japan.
}

(Received August 25, 2021; Accepted October 31, 2021)

\begin{abstract}
We report a rare case of suppurative thrombophlebitis of the posterior neck caused by Streptococcus constellatus. A 69-year-old female patient was admitted to the hospital with neck pain and fever, which had persisted for 16 days prior to hospitalization. On day 1 (day of admission), blood cultures (later identifying S. constellatus) were performed, and ceftriaxone (CTRX) IV (2 g SID) was started. On day 3, suppurative thrombophlebitis of the posterior neck was diagnosed by CT scan. The antimicrobials were changed from CTRX to ampicillin/sulbactam IV (12 g QID) to guard against the possibility of complicated infection with Fusobacterium spp. or Prevotella spp. On day 17, a CT scan revealed that the thrombus remained. Therefore, oral edoxaban (30 mg SID) was started. On day 27 , the patient was discharged after her medication was changed to oral amoxicillin/clavulanate (1500 mg/375 mg TID). On day 33, the amoxicillin/clavulanate was changed to oral cefaclor (1500 mg TID) and edoxaban was discontinued due to itching. On day 45, the course of cefaclor was completed. The patient went on to follow an uneventful course with no relapses or complications for two years since the conclusion of treatment. These results suggest that when a patient presents with persistent neck pain accompanied by fever, suppurative thrombophlebitis of the posterior neck should be considered. In antimicrobial therapy, the treatment could be switched from intravenous to oral. In addition, direct-acting oral anticoagulants may be an alternative to other forms of anticoagulants.
\end{abstract}

Key words_-Streptococcus constellatus; suppurative thrombophlebitis; oral switch; amoxicillin/clavulanate; cefaclor; edoxaban

\section{INTRODUCTION}

Streptococcus constellatus belongs to the Streptococcus anginosus group. ${ }^{1}$ It can infect the skin, soft tissues, intra-abdominal area, and respiratory system. ${ }^{2}$ However, there have been few reported cases of suppurative thrombophlebitis in Japan. Suppurative thrombophlebitis can occur as a result of Lemierre's syndrome. ${ }^{3)}$ It is a refractory condition with many complications, including thromboembolism. It requires prompt and reliable treatment. In addition, there have been limited reports of oral antimicrobial switching and anticoagulation using direct-acting oral anticoagulants (DOACs) in cases of thrombophlebitis.

Here, we present the first case of posterior neck thrombophlebitis caused by $S$. constellatus and a literature review to objectively assess the validity of our chosen interventions.

\footnotetext{
*e-mail: taka19830817@gmail.com
}

\section{CASE REPORT}

A 69-year-old woman visited her local doctor for neck and nasopharynx pain that had persisted for the preceding two weeks. She was diagnosed with a nasopharyngeal infection and prescribed oral levofloxacin (500 mg SID) . The nasopharyngeal symptoms improved but her neck pain persisted. She also contracted a fever the day before she presented to our hospital. She had a medical history of chronic sinusitis. The findings of a physical examination on admission were as follows: height: $156 \mathrm{~cm}$; body weight: 50 $\mathrm{kg}$; blood pressure: $102 / 71 \mathrm{mmHg}$; pulse: 145 beats/ min; body temperature: $39.8^{\circ} \mathrm{C}$; respiratory rate: 26 breaths/min; saturation of percutaneous oxygen: 98\% (room air) ; consciousness: clear. A head examination revealed strong eye pain on the left side. The patient's cardiac, respiratory, abdominal, and neurological examinations were normal. Laboratory examinations on admission were as follows: white blood cell count: $19.4 \times 10^{3} / \mu \mathrm{L}$; C-reactive protein: 19.87 
$\mathrm{mg} / \mathrm{dL}$; procalcitonin: $14.10 \mathrm{ng} / \mathrm{mL}$; serum creatinine: $0.55 \mathrm{mg} / \mathrm{dL}$ (Supplementary Table 1). Contrast-enhanced computed tomography (CT) findings revealed thrombus in a vein in the left posterior neck and the scan confirmed the presence of left sphenoidal sinusitis (Supplementary Fig. 1). The chest and abdomen were normal. Transthoracic echocardiography (TTE) on day 3 findings revealed noninfectious vegetations on all heart valves. Two sets of blood cultures taken on admission found $S$. constellatus (Supplementary Table 2) .

The clinical course after hospitalization is shown in Supplementary Fig. 2. On day 1 (day of admission), blood cultures were taken and ceftriaxone (CTRX) IV (2 g SID) was started. On day 3, the radiology department evaluated the cervical to abdominal contrast CT performed at the time of admission, which revealed the thrombus in the posterior neck vein. The patient's pain site corresponded to the thrombus site, furthermore, no symptom that indicated the infection of other organs was observed. There, the patient was diagnosed suppurative thrombophlebitis of the posterior neck. CTRX was changed to ampicillin/sulbactam (ABPC/SBT) IV (12 g QID) to guard against the possibility of complicated infection with Fusobacterium spp. or Prevotella spp. On day 6, the laboratory reported that $S$. constellatus had been identified in the blood culture taken on day 1 and ABPC/SBT was continued. The results of a second blood culture (taken on day 6) were negative. At that time, the pharmacists performed a literature review of thrombophlebitis caused by $S$. constellatus and suggested suitable antimicrobial agents and treatment duration. On day 17, a contrast-enhanced CT scan of the head and neck was performed. This revealed that the thrombus in the posterior neck was still present but shrinking. In addition, thrombus in the sigmoid sinus and left sphenoid sinusitis were found (Supplementary Fig. 3). The pharmacists suggested edoxaban based on interactions, efficacy, and safety. Therefore, oral edoxaban (30 mg SID) was started. On day 27, ABPC/SBT was changed to oral amoxicillin/clavulanate (AMPC/CVA) $\quad(1500 \mathrm{mg} / 375 \mathrm{mg}$ TID), and the patient was discharged. There were no adverse events associated with the use of CTRX and ABPC/SBT. However, on day 33, itching occurred with no drug-induced rash. The patient had an eosinophil count of $58 / \mu \mathrm{L}$. Based on these symptoms and findings, the dermatologist diagnosed seborrheic eczema. The patient requested changes in the prescribed antimicrobials. Therefore, the pharmacists recommended cefaclor (CCL) instead of CVA/ AMPC for $S$. constellatus. In addition, they suggested the use of another antimicrobial in combination with CCL for anaerobic bacteria not susceptible to CCL. However, the patient favored CCL instead of combination therapy. Therefore, AMPC/CVA was changed to oral CCL (1500 mg TID), and the edoxaban, although not known to be associated with skin symptoms, was also discontinued at the patient's request. Subsequently, the pruritus improved. CCL treatment was completed on day 45 . The patient has followed an uneventful course for two years since the conclusion of treatment.

\section{DISCUSSION}

In this study, we encountered a case of suppurative thrombophlebitis of the posterior neck caused by $S$. constellatus. S. constellatus inhabits the human oral cavity, pharynx, and gastrointestinal tract. In a previous study, ${ }^{2)}$ of 56 isolates in which $S$. constellatus was detected, 39 (66\%) were recovered from in leached or aspirated abscesses, suggesting that this microorganism tends to form abscesses.

Using Ichushi-Web and PubMed, we found 14 reports ${ }^{4-17)}$ of suppurative thrombophlebitis caused by $S$. constellatus in a search conducted on July 11, 2021 (Table 1).

The infection was to the mouth, throat, and upper respiratory tract in $71 \%(10 / 14)$ of these cases. This corresponded to the organs where $S$. constellatus is most frequently detected (i.e., the respiratory system) . 2) It was difficult to identify the site of infection in this patient because bacteriological tests of nasal discharge were not performed. However, the CT showed sphenoid sinusitis, which was suspected to be the site of infection in this patient. Regarding the site of thrombus formation (including duplication), $57 \%(8 / 14)$ were found in the base of the skull, and this case is the first report of thrombophlebitis in the posterior jugular vein.

Regarding the choice of antimicrobial agents, previous reports ${ }^{4-17)}$ have shown that antimicrobial agents are effective against both $S$. constellatus and anaerobic bacteria. This may be why many cases developed abscesses (cases 3, 4, 6, 7, 13, and 14) or Lemierre's syndrome caused by bacteria such as Fusobacterium spp. and Prevotella spp. that produce 
Table 1. Case Reports of Suppurative Thrombophlebitis Caused by Streptococcus constellatus in the Literature

\begin{tabular}{|c|c|c|c|c|c|c|c|c|c|}
\hline Case & Age & Sex & $\begin{array}{l}\text { Presence } \\
\text { of LS }\end{array}$ & $\begin{array}{l}\text { Source of } \\
\text { infection }\end{array}$ & $\begin{array}{l}\text { Site of } \\
\text { thrombosis }\end{array}$ & $\begin{array}{l}\text { Antimicrobial agents } \\
\text { (Duration) }\end{array}$ & $\begin{array}{l}\text { Anticoagulants } \\
\text { (Duration) }\end{array}$ & Prognosis & Year \\
\hline 1 & 39 & Male & $(-)$ & $\begin{array}{l}\text { Sphenoid } \\
\text { sinusitis }\end{array}$ & $\begin{array}{l}\text { Cavernous } \\
\text { sinus }\end{array}$ & PCG (42) & $(-)$ & Cure & $2003^{4)}$ \\
\hline 2 & 20 & Male & $(-)$ & Appendicitis & SMV & $\begin{array}{l}\text { Broad spectrum antibiotics } \\
\text { (NA) }\end{array}$ & Heparin (3), Warfarin (28) & Cure & $2006^{5)}$ \\
\hline 3 & 56 & Female & $(+)$ & Orbital cellulitis & $\begin{array}{l}\text { Cavernous } \\
\text { sinus }\end{array}$ & $\mathrm{ABPC} / \mathrm{SBT}$ (49) & $(-)$ & Cure & $2007^{6)}$ \\
\hline 4 & 54 & Female & $(+)$ & Dental abscess & $\begin{array}{l}\text { Cavernous } \\
\text { sinus }\end{array}$ & $\begin{array}{l}\text { MEPM + CLDM (NA), } \\
\text { CLDM (NA) (total 42) }\end{array}$ & $\begin{array}{l}\text { Enoxeparin (NA), Aspirin } \\
\text { (NA), Warfarin (NA) } \\
\text { (total 180). }\end{array}$ & Cure & $2009^{7)}$ \\
\hline 5 & 51 & Female & $(+)$ & Dens infection & $\begin{array}{l}\text { Cavernous } \\
\text { sinus }\end{array}$ & $\begin{array}{l}\text { CTX (3), MEPM (1), } \\
\text { ABPC/SBT (32), } \\
\text { AMPC (8) }\end{array}$ & $(-)$ & Cure & $2010^{8)}$ \\
\hline 6 & 24 & Male & $(+)$ & Dental abscess & $\begin{array}{l}\text { Iliofemoral } \\
\text { vein }\end{array}$ & $\begin{array}{l}\text { Flucloxacilli + GM (NA) } \\
\text { VCM + GM (NA), PCG + } \\
\text { GM (NA) }\end{array}$ & $\begin{array}{l}\text { Tinzaparin (16), Warfarin } \\
\text { (NA) }\end{array}$ & Cure & $2011^{9)}$ \\
\hline 7 & 45 & Male & $(-)$ & Rhinosinusitis & $\begin{array}{l}\text { Cavernous } \\
\text { sinus }\end{array}$ & $\begin{array}{l}\text { CTRX + VCM (NA), } \\
\text { CTRX (NA), Thiam- } \\
\text { phenicol (NA) }\end{array}$ & $\begin{array}{l}\text { Low molecular weight } \\
\text { heparin (NA), Warfarin } \\
\text { (NA) }\end{array}$ & Cure & $2012^{10)}$ \\
\hline 8 & 76 & Male & $(+)$ & Neck abscesses & $\begin{array}{l}\text { Internal } \\
\text { jugular vein }\end{array}$ & $\begin{array}{l}\text { MEPM (NA), PIPC/TAZ } \\
\text { (NA) }\end{array}$ & $\begin{array}{l}\text { Heparin (40), Dabigatran } \\
(13)\end{array}$ & Cure & $2014^{11)}$ \\
\hline 9 & 52 & Female & $(-)$ & Leptomeningitis & $\begin{array}{l}\text { Cavernous } \\
\text { Sinus }\end{array}$ & $\begin{array}{l}\text { CTRX + MNZ + VCM } \\
\text { (NA), CTRX (NA), MNZ } \\
+ \text { VCM (NA), MEPM } \\
\text { (NA) }\end{array}$ & $(-)$ & Cure & $2014^{12)}$ \\
\hline 10 & 60 & Female & $(+)$ & Unknown origin & $\begin{array}{l}\text { Ovarian } \\
\text { vein }\end{array}$ & $\begin{array}{l}\text { CTRX }+\mathrm{GM}+\mathrm{MNZ} \\
\text { (NA), ABPC/SBT (NA), } \\
\text { AMPC + CLDM (10) }\end{array}$ & $\begin{array}{l}\text { Heparin (NA), Warfarin } \\
(90)\end{array}$ & Cure & $2015^{13)}$ \\
\hline 11 & 54 & Female & $(+)$ & Cavity & $\begin{array}{l}\text { Cavernous } \\
\text { sinus }\end{array}$ & $\begin{array}{l}\text { CTRX (4), MEPM (7), } \\
\text { ABPC/SBT (6), PIPC/ } \\
\text { TAZ (10), Oral antibiotics } \\
\text { (NA) }\end{array}$ & $\begin{array}{l}\text { Heparin (11), Heparin }+ \\
\text { warfarin (9), Warfarin } \\
\text { (NA) }\end{array}$ & Cure & $2015^{14)}$ \\
\hline 12 & 59 & Male & $(-)$ & Diverticulitis & Portal vein & MEPM (1) & Heparin (1) & Dead & $2016^{15)}$ \\
\hline 13 & 70 & Female & $(+)$ & $\begin{array}{l}\text { Bezold's } \\
\text { abscesses }\end{array}$ & $\begin{array}{l}\text { Internal } \\
\text { jugular vein }\end{array}$ & CTRX (33), AMPC (84) & $\begin{array}{l}\text { Heparin (NA), Warfarin } \\
\text { (NA) }\end{array}$ & Cure & $2018^{16)}$ \\
\hline 14 & 62 & Female & $(+)$ & $\begin{array}{l}\text { Masticator } \\
\text { space abscess }\end{array}$ & $\begin{array}{l}\text { Cavernous } \\
\text { sinus }\end{array}$ & $\begin{array}{l}\mathrm{PIPC} / \mathrm{TAZ}+\mathrm{MNZ}+ \\
\text { VCM (2), ABPC/SBT } \\
\text { (NA), ERPM (NA) }\end{array}$ & $(-)$ & Cure & $2020^{17)}$ \\
\hline 15 & 69 & Female & $(-)$ & $\begin{array}{l}\text { Sphenoidal } \\
\text { sinusitis }\end{array}$ & $\begin{array}{l}\text { Posterior } \\
\text { jugular vein }\end{array}$ & $\begin{array}{l}\text { CTRX (2), ABPC/SBT } \\
\text { (23), AMPC/CVA (7), } \\
\text { CCL (13) }\end{array}$ & Edoxaban (17) & Cure & $\begin{array}{l}\text { This } \\
\text { case }\end{array}$ \\
\hline
\end{tabular}

Abbreviations: $\mathrm{LS}=$ Lemierre's syndrome; $\mathrm{SMV}=$ superior mesenteric vein $\mathrm{PCG}=$ penicillin $\mathrm{G} ; \mathrm{NA}=$ not available; $\mathrm{ABPC} / \mathrm{SBT}=\mathrm{ampicillin} / \mathrm{sulbactam}$; $\mathrm{MEPM}=$ meropenem; $\mathrm{CLDM}=$ clindamycin $\mathrm{CTX}=$ cefotaxime; $\mathrm{AMPC}=$ amoxicillin; $\mathrm{GM}=$ gentamicin; $\mathrm{VCM}=$ vancomycin; $\mathrm{PIPC} / \mathrm{TAZ}=$ piperacillin $/$ tazobactam; $\mathrm{CTRX}=$ ceftriaxone; $\mathrm{MNZ}=$ metronidazole; $\mathrm{ERPM}=$ ertapenem; $\mathrm{AMPC} / \mathrm{CVA}=$ amoxicillin $/$ clavulanate; $\mathrm{CCL}=$ cefaclor.

$\beta$-lactamase (cases $3,4,5,6,7,10,11,13$, and 14 ). In this patient, we avoided the possibility of complicated infections with $S$. constellatus and other bacteria such as anaerobic and $\beta$-lactamase-producing bacteria, by administering penicillin antibiotics combined with $\beta$ lactamase inhibitors.

Regarding the duration of intravenous antimicrobial therapy, a previous study ${ }^{18)}$ reported that no relapses occurred when switching to oral antimicrobial agents after two to three weeks of treatment with intravenous antimicrobials. Accordingly, this patient was switched after 19 days of negative blood cultures. A switch to oral antimicrobial agents was reported in $29 \%(4 / 14)$ of previous studies and in three cases the switch was to amoxicillin (cases 5, 10, and 13). However, there are limited reports on switching from 
intravenous therapy to oral antimicrobial agents. In this patient, ABPC/SBT was changed to AMPC/ CVA on day 27 to prevent mixed infection with anaerobic bacteria. Based on the literature review, the duration of treatment for suppurative thrombophlebitis caused by $S$. constellatus is approximately 42 days in most cases. ${ }^{4,6-8,16)}$ Accordingly, the duration of treatment for this patient was also set at 42 days, and treatment was completed at this time.

AMPC/CVA was changed to CCL in this patient. The CCL did not exacerbate the pruritus. Haslam et al. reported no adverse events in response to firstgeneration cephalosporins administered to nonimmunoglobin E penicillin-allergic cases. ${ }^{19)}$ Thus, it is presumed that this patient did not have an allergic reaction to AMPC/CVA. However, the treatment against anaerobic bacteria was interrupted when CCL was used as an alternative. Referring to the outcomes of cases 5 and 13, who were cured with AMPC without any anaerobic activity, CCL was selected and the condition of the patient in the present case improved.

On the basis of the literature review, the duration of anticoagulation treatment often exceeds 28 days. However, 5 of the 10 cases with thrombus formation in the skull base and the head and neck region were treated successfully, although any anticoagulant was not administered because of the risk of bleeding. Thus, anticoagulant therapy has not been definitively established for suppurative thrombophlebitis in the skull base and the head and neck region. Owing to pruritus, the patient could only receive anticoagulants for 17 days. Subsequently, the patient showed no evidence of multiple emboli. A previous report and the present case suggest that suppurative thrombophlebitis of the skull base and the head and neck region can be treated successfully without having to perform anticoagulation therapy for $>28$ days. However, further study is warranted (Supplementary Table 3 for the use of anticoagulants).

Regarding the types of anticoagulants administered, most previously reported cases were switched from intravenous anticoagulants to warfarin. However, there was a concern that the management of warfarin would be complicated because of the need for dosage determination based on blood tests. Therefore, we reviewed the results of treatment with DOACs, which require no blood tests and allow for fixed doses, as an alternative to warfarin, and found a successful case. ${ }^{11)}$ However, there are limited reports on the usage of DOACs for treating thrombophlebitis. In addition, macrolides are prescribed by many Japanese physicians for long-standing sinusitis. Since this patient had sinusitis, future treatment with macrolides was a possibility. However, macrolides are problematic because of their CYP inhibitory effects. ${ }^{20)}$ Unlike other DOACs, edoxaban does not increase blood concentration when combined with CYP inhibitors. ${ }^{21)}$ However, concomitant use of CYP inhibitors increases the blood concentration of warfarin or direct oral factor Xa inhibitors other than edoxaban. Low-dose edoxaban is similar in effectiveness to warfarin and causes significantly less bleeding in venous thrombosis such as venous thromboembolism in elderly patients with low body weight. ${ }^{22)}$ Therefore, the pharmacists recommended the use of edoxaban to the physician, and the drug was selected for this patient. Regarding edoxaban, bacterial embolism to distant organs was not developed, and its efficacy was suggested. No adverse events were reported as no bleeding complications were observed. The cost of edoxaban $(115,164$ yen) was higher than that of warfarin (823 yen) (Supplementary Table 3 shows the calculation of the total cost of anticoagulants). However, the duration of treatment for suppurative thrombophlebitis is short with anticoagulants. In addition, considering increased bleeding events and blood sampling frequency for warfarin, ${ }^{23)}$ edoxaban may be more cost-effective than warfarin. However further study is needed on the types of anticoagulants that are most safe and effective for the treatment of suppurative thrombophlebitis.

It should be noted that this report was limited to a single case.

\section{CONCLUSION}

To our knowledge, this study is the first to report a case of thrombus in the patient's posterior jugular vein caused by $S$. constellatus. When patients present with persistent neck pain and fever, posterior suppurative thrombophlebitis should be considered. There are limited reports on switching from intravenous therapy to oral antimicrobials and the administration of DOACs for suppurative thrombophlebitis. The treatment could be switched to oral antimicrobial therapy from intravenous therapy. The role of anticoagulation is unclear but DOACs may be an alternative. 
Conflicts of Interest The authors declare no conflicts of interest.

Supplementary Materials The online version of this article contains supplementary materials.

\section{REFERENCES}

1) Kawamura Y., Nippon Saikingaku Zasshi, 53, 493-507 (1998).

2) Clarridge J. E. 3rd, Attorri S., Musher D. M., Hebert J., Dunbar S., Clin. Infect. Dis., 32, 1511-1515 (2001).

3) Chirinos J. A., Garcia J., Alcaide M. L., Toledo G., Baracco G. J., Lichtstein D. M., Am. J. Cardiovasc. Drugs, 6, 9-14 (2006) .

4) Chang W. N., Chen S. D., Lui C. C., Huang C. R., Lu C. H., J. Formos. Med. Assoc., 102, 733-736 (2003).

5) Sakalkale R., Reeve P., N.Z. Med. J., 119, U1984 (2006) .

6) Hoshino C., Satoh N., Sugawara S., Kuriyama C., Kikuchi A., Ohta M., Intern. Med., 46, 317-323 (2007).

7) Jones R. G., Arnold B., BMJ Case Rep., bcr03.2009.1671 (2009).

8) Yamaguchi M., Nishizawa H., Yasumoto T., Kimura T., Takeuchi Y., Takeshita A., Takase T., Fujimoto H., Nakano M., Fukunaga M., Intern. Med., 49, 753-757 (2010) .

9) Sulaiman L., Hunter J., Farquharson F., Reddy H., Br. J. Anaesth., 106, 65-68 (2011).

10) Imholz B., Becker M., Lombardi T., Scolozzi P., Dentomaxillofac. Radiol., 41, 525-528 (2012).

11) Shimada M., Morinaga Y., Kitazaki T., Fukuda M., Hashiguchi K., Yanagihara K., Kohno
S., Jpn. J. Infect. Dis., 67, 488-489 (2014) .

12) Chung H. C., Park S. H., Kim E. S., Kim Y. I., Lee S. H., Nam-Goong I. S., J. Bone Metab., 21, 227-232 (2014).

13) Haidar A., Haddad A., Naqvi A., Onyesoh N. U., Malik R., Williams M., Case Rep. Infect. Dis., 495898 (2015).

14) Nishida A., Ogata T., Kudo M., Fukuhara K., Fukae J., Tsuboi Y., Clin. Neurol., 55, 483489 (2015).

15) Kashiura M., Sugiyama K., Akashi A., Hamabe Y., Acute Med. Surg., 3, 404-406 (2016).

16) Yaita K., Sugi S., Hayashi M., Koga T., Ebata T., Sakai Y., Kaieda S., Ida H., Watanabe H., Medicine, 97, e11228 (2018).

17) Rohowetz L. J., Gratton S. M., Dansdill D., Miller C. J., Dubin S., Am. J. Ophthalmol. Case Rep., 18, 100592 (2020).

18) Mertz D., Khanlari B., Viktorin N., Battegay M., Fluckiger U., Clin. Infect. Dis., 46, 741744 (2008).

19) Haslam S., Yen D., Dvirnik N., Engen D., Iowa Orthop. J., 32, 100-103 (2012) .

20) Rodvold K. A., Clin. Pharmacokinet., 37, 385-398 (1999).

21) Bathala M. S., Masumoto H., Oguma T., He L., Lowrie C., Mendell J., Drug Metab. Dispos., 40, 2250-2255 (2012).

22) Büller H. R., Décousus H., Grosso M. A., Mercuri M., Middeldorp S., Prins M. H., Raskob G. E., Schellong S. M., Schwocho L., Segers A., Shi M., Verhamme P., Wells P., $N$. Engl. J. Med., 369, 1406-1415 (2013).

23) Clay E., Jamotte A., Verhamme P., Cohen A. T., Van Hout B. A., Gumbs P., J. Mark. Access Health Policy, 6, 1495974 (2018). 